\title{
An experimental and numerical study of ductile failure under quasi-static and impact loadings of Inconel 718 nickel-base superalloy
}

\author{
Borja Erice María Jesús Pérez-Martín , Francisco Gálvez
}

\begin{abstract}
A B S T R A C T
A numerical and experimental study of ballistic impacts at various temperatures on precipitation hardened Inconel 718 nickel-base superalloy plates has been performed. A coupled elastoplastic-damage constitutive model with Lode angle dependent failure criterion has been implemented in LS-DYNA nonlinear finite element code to model the mechanical behaviour of such an alloy. The ballistic impact tests have been carried out at three temperatures: room temperature $\left(25^{\circ} \mathrm{C}\right), 400{ }^{\circ} \mathrm{C}$ and $700{ }^{\circ} \mathrm{C}$. The numerical study showed that the mesh size is crucial to predict correctly the shear bands detected in the tested plates. Moreover, the mesh size convergence has been achieved for element sizes on the same order that the shear bands. The residual velocity as well as the ballistic limit prediction has been considered excellent for high temperature ballistic tests. Nevertheless, the model has been less accurate for the numerical simulations performed at room temperature, being though in reasonable agreement with the experimental data. Additionally, the influence that the Lode angle had on quasi-static failure patterns such as cup-cone and slanted failure has been studied numerically. The study has revealed that the combined action of weakened constitutive equations and Lode angle dependent failure criterion has been necessary to predict the previously-mentioned failure patterns.
\end{abstract}

\section{Introduction}

Current aero-engine standards oblige manufacturers to pass severe tests in order to ensure the security of such engines. One of these tests is the containment test. The basic idea is that if something that can damage the engine happens during take-off, flight or landing, all the damaged pieces must be contained within the casing. Whatever the initiator is, the last and most dangerous situation is the blade-off event. A blade-off event is characterised by the failure of a blade corresponding to any of the rotating parts of the engine. Due to the strong centrifugal forces that the rotating parts are subjected to, if a blade is damaged in any unexpected process its load carrying area will be reduced making the blade more prone to an abrupt failure. If sudden failure occurs, the blade transforms its internal energy into kinetic energy. This makes the blade turn into a projectile with a potentially dangerous radial velocity. The radial velocity depends on the rotational speed and the radius of gyration of the component. Depending on those factors such velocity could reach ballistic velocity values. If this happens, the casing is the only barrier between the aircraft wing and the blade. Therefore, the casing acts as a shield.

The containment tests try to reproduce artificially a blade-off event. For that purpose, once the engine is properly instrumented in a controlled environment, an explosive charge is planted in the base (root or fir-tree) of a blade. When the engine is running at the desired rotational speed the charge is activated, releasing the blade from the disk to which it belongs. The test is considered successful if the casing holds and is not perforated. As could be expected, these real-scale tests are expensive, since certification implies testing an engine with all its components. Hence, repetition of the test on several occasions to perform parametric studies (thickness, material, among others) on the casing is not an option. To cope with this issue, numerical simulations using the finite element method (FEM) of this type of tests are considered. The most suitable finite element code for such a purpose is an explicit non-linear code such as the commercial code LS-DYNA. In order to simulate with relative precision the containment test, proper material models are necessary. 
The precipitation hardened Inconel 718 nickel-base superalloy is one of the most common materials employed for the manufacturing of turbine casings. Therefore, the mechanical behaviour of such an alloy is of especial interest. The operating temperatures of the turbine casings generally range from $400{ }^{\circ} \mathrm{C}$ to $800^{\circ} \mathrm{C}$. In order to assess the ballistic performance of the material at such temperatures, the impact tests were carried out at three temperatures: $25^{\circ} \mathrm{C}, 400{ }^{\circ} \mathrm{C}$ and $700^{\circ} \mathrm{C}$ on $1.6 \mathrm{~mm}$ plates. The high temperature experiments were carried out employing a hollow cylinder shaped ballistic furnace designed especially for the current investigation. The furnace, installed in the impact chamber allowed having the plates at the desired temperature. The experiments showed the outstanding performance of the impacted alloy against the temperature. Compared to the room temperature tests, the ballistic limit almost remains the same for $400^{\circ} \mathrm{C}$, while it drops slightly in $35 \mathrm{~m} / \mathrm{s}$ for the tests conducted at $700^{\circ} \mathrm{C}$.

Recent studies $[1-6]$ have shown the key role that the third deviatoric invariant plays in the failure of ductile materials. Furthermore, the introduction of such a parameter directly or indirectly, by means of coupled relationships, in the constitutive equations has been proven to be crucial to predict correctly failure patterns observed in real cases. Even though new or modified models, such as the previously-mentioned, have been developed in the recent years, none of them have dealt with impact problems. In this article the capabilities of the coupled elastoplastic-damage constitutive model with Lode angle dependent failure criterion for high strain rate phenomena and ballistic impact postulated by Erice and Gálvez [7] are investigated. The third deviatoric invariant dependency was included in the model with a Lode angle dependent function [8] inserted in the equivalent plastic strain to failure expression of the Johnson-Cook failure criterion [9]. The weakening in the elastic law and in the Johnson-Cook-type constitutive relation [10] implicitly introduced the Lode angle dependency in the elastoplastic behaviour. The model, calibrated for the precipitation hardened Inconel 718 nickel-base superalloy, showed that it was able to capture complex failure patterns such as cup-cone or slanted fractures.

The calibrated coupled model, implemented in LS-DYNA [11] non-linear finite element code, was used to perform a numerical failure pattern prediction analysis in quasi-static loading conditions. Previous studies $[5,12,13]$ have assessed the influence of the triaxiality and Lode angle on the failure of ductile materials. All of them agree that the Lode angle is responsible in some way of the transition between flat and slanted failures. The Lode angle and mesh size dependency on the prediction of cup-cone and slanted failure patterns have been analysed. The pattern prediction was ineffective for relatively large mesh sizes $(\sim 68 \mu \mathrm{m})$. Unfortunately, a significantly smaller mesh size was needed to reproduce the desired failure patterns $(\sim 21 \mu \mathrm{m})$. The combined effect of weakened constitutive equations and Lode angle dependent failure criterion was proven effective to predict such patterns.

Numerical simulations of the ballistic impacts on precipitation hardened Inconel 718 nickel-base superalloy $1.6 \mathrm{~mm}$ thickness plates at three temperatures, $25^{\circ} \mathrm{C}, 400{ }^{\circ} \mathrm{C}$ and $700{ }^{\circ} \mathrm{C}$, were performed to check the validity of the new material model under impact loadings. The objective was to predict the residual velocities measured on the experiments. For continuum material models such as the one presented here, the element size in impact problems still remains an issue. In order to address such an issue, a mesh sensitivity study was carried out. The analysis performed showed that the element size was vital to predict the adiabatic shear bands responsible of the failure. Unless those bands were predicted neither residual velocities nor ballistic limits were correctly obtained. An additional geometrically-based element erosion criterion was implemented to get rid of highly-distorted elements that slowed down the calculation time.

\section{Material description}

The polycrystalline nickel-base superalloys are typically used in components that work in aggressive media and are subjected to severe temperatures. The key feature of these alloys is that they are able to keep their mechanical properties at relatively high temperatures. This makes them an ideal candidate to manufacture aero-engine components such as casings or blades. The plates tested in the present investigation were machined from rolled $1.6 \mathrm{~mm}$ sheet that was heat treated to achieve the precipitation-hardened or aged state. The certificated chemical composition for the precipitation hardened Inconel 718 is shown in Table 1.

\section{Ballistic impact tests}

\subsection{Experimental set-up}

Ballistic impact tests on $1.6 \mathrm{~mm}$ thickness precipitation hardened Inconel 718 nickel-base superalloy square plates were performed at three temperatures: $25^{\circ} \mathrm{C}, 400{ }^{\circ} \mathrm{C}$ and $700{ }^{\circ} \mathrm{C}$. Those temperatures were intended to simulate the working environment of a low pressure turbine on a modern aero-engine, hence real operating conditions. The experimental set-up can be observed in Fig. 1 (a). A single-stage gas gun operated either with helium or compressed air was employed to shoot AISI 52100 steel $5.55 \mathrm{~mm}$ diameter spherical projectiles. The projectiles were shot with initial velocities within 300 and $800 \mathrm{~m} / \mathrm{s}$.

The impact chamber was equipped with an in-house made cylindrical-shaped furnace which can be seen in Fig. 1(b). In order to ensure that the plate was at the desired temperature, the furnace was controlled with a thermocouple in contact with the target (see Fig. 1(c)). The sliding frame in which the plate was mounted permitted the movement along the symmetry axis of the furnace. Therefore, the plate could easily be inserted in the furnace or extracted out of it. The temperature was set to increase with a slope of $5{ }^{\circ} \mathrm{C} / \mathrm{min}$ until the target temperature was reached and then it was maintained for 30 minutes. The caps located in each end of the furnace were then removed to shoot the projectile.

The initial velocity readings were obtained with two solid-state laser screens, whereas the residual velocity of the plug was measured with two electrically-activated screens. An additional series of tests was carried out at room temperature. In this additional experimental campaign, the furnace was removed and the residual velocities were measured using a Phantom v12 highspeed camera. The videos were recorded with a resolution of $512 \times 128$ pixels at $80,000 \mathrm{fps}$ with and exposure of $10 \mu \mathrm{s}$. The measurements obtained from the recordings confirmed that the electrically-activated screens were giving correct residual velocity readings as can be observed in Fig. 2. The blue solid circles correspond to the camera measurements, whereas the blue hollow circles correspond to the electrically-activated screens readings. The results from both series, camera-measured and screen-measured, were virtually identical.Fig. 3

Table 1

Certificated chemical composition in \%wt. of Inconel 718 nickel-base superalloy.

\begin{tabular}{lllllllll}
\hline $\mathrm{Cr}$ & $\mathrm{Ni}$ & $\mathrm{Mo}$ & $\mathrm{Nb}$ & $\mathrm{Ti}$ & $\mathrm{Al}$ & $\mathrm{F}$ & $\mathrm{C}$ & $\mathrm{Cu}$ \\
\hline 19.0 & 52.5 & 3.0 & 5.1 & 0.9 & 0.5 & 18.5 & $0.08 \mathrm{max}$ & $0.15 \mathrm{max}$ \\
\hline
\end{tabular}




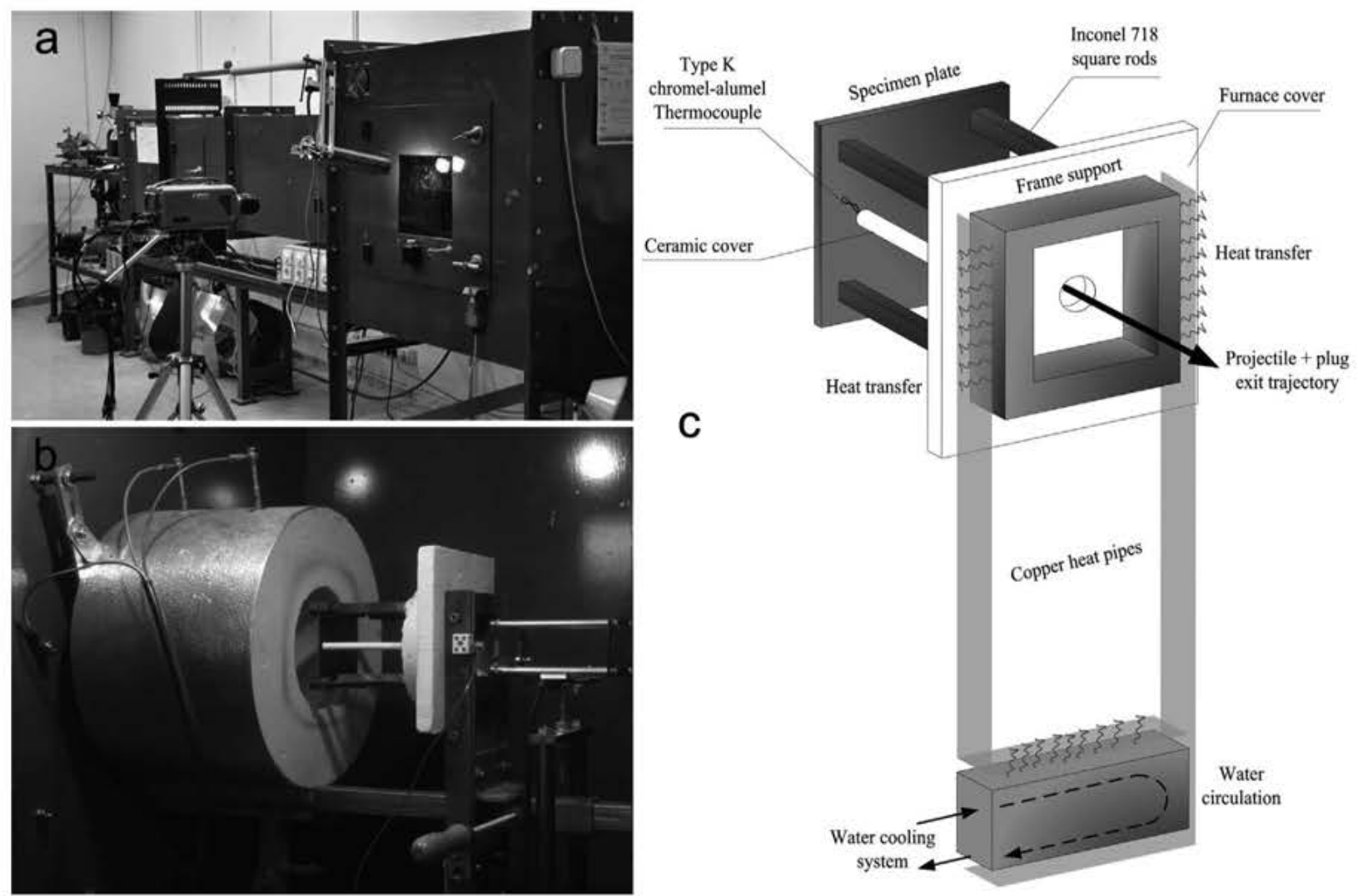

Fig. 1. (a) A general overview of the experimental set-up and (b) a detail of the impact chamber interior. (c) Plate mounting system scheme.

\subsection{Results}

The residual vs. initial velocity curves for each one of the test series performed are plotted in Fig. 2. The experimental plug

Experiments $25^{\circ} \mathrm{C}$ HS camera

O Experiments $25^{\circ} \mathrm{C}$ EA screens - Recht-Ipson model $25^{\circ} \mathrm{C}$

口 Experiments $400^{\circ} \mathrm{C}$ EA screens - - Recht-Ipson model $400^{\circ} \mathrm{C}$

$\diamond$ Experiments $700^{\circ} \mathrm{C}$ EA screens -- Recht-Ipson model $700^{\circ} \mathrm{C}$

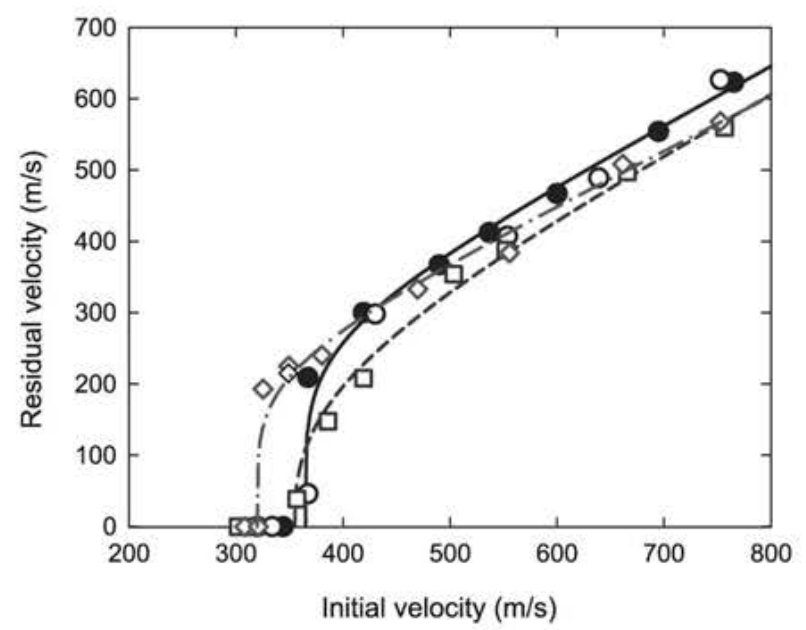

Fig. 2. Experimental residual vs. initial velocity curves for ballistic impact tests on precipitation hardened Inconel 718 plates at various temperatures. The room temperature tests were measured employing the electrically-activated screens (EA screens) and a high-speed camera (HS camera). (For interpretation of the references to colour in this figure legend, the reader is referred to the web version of this article.) residual velocities $v_{r}$ were fitted employing a Recht-Ipson-type model [14] later modified by Lambert et al. [15] as:

$v_{r}=a\left(v_{0}^{p}-v_{b l}^{p}\right)^{1 / p}$

where $a$ and $p$ are fitting constants. The ballistic limit $v_{b l}$, was conveniently adjusted for best fitting results. The Recht-Ipson-type model fitting constants and ballistic limits for the test series carried out at $25^{\circ} \mathrm{C}, 400{ }^{\circ} \mathrm{C}$ and $700{ }^{\circ} \mathrm{C}$ can be found in Table 2 .

The ballistic limit remained almost unchanged $(355-365 \mathrm{~m} / \mathrm{s}$ ) when rising the plate temperature from $25{ }^{\circ} \mathrm{C}$ to $400{ }^{\circ} \mathrm{C}$. Nevertheless, the plug residual velocities were higher for the test series performed at $25^{\circ} \mathrm{C}$. Therefore, the alloy presented an increase on ballistic performance at $400{ }^{\circ} \mathrm{C}$. The test series carried out at $700^{\circ} \mathrm{C}$ showed that the material had similar behaviour as at $400{ }^{\circ} \mathrm{C}$ for initial velocities above $650 \mathrm{~m} / \mathrm{s}$. However, the ballistic performance of it decreased noticeable for initial velocities below $500 \mathrm{~m} / \mathrm{s}$. Such a performance was accompanied by an obvious decrease on the ballistic limit $(320 \mathrm{~m} / \mathrm{s})$.

A non-perforated plate tested at room temperature is shown in Fig. 4 (a). The augmented detail below, which was taken with an optical microscope, zooms in the zone where an incipient crack was formed by shear localisation. Similar behaviour was previously reported by DeMange et al. [16] on blunt projectile impacted Inconel 718 plates. Perforated plates stroke with similar initial velocities at $25{ }^{\circ} \mathrm{C}, 400{ }^{\circ} \mathrm{C}$ and $700{ }^{\circ} \mathrm{C}$ are shown in Fig. 4(b)-(d) respectively. The plate residual deformation seems to be the same for the targets tested at $25^{\circ} \mathrm{C}$ and $400{ }^{\circ} \mathrm{C}$ as can be observed in Fig. 4(b) and (c). Conversely, the plate tested at the highest temperature had almost no residual deformation (see Fig. 4(d)). 


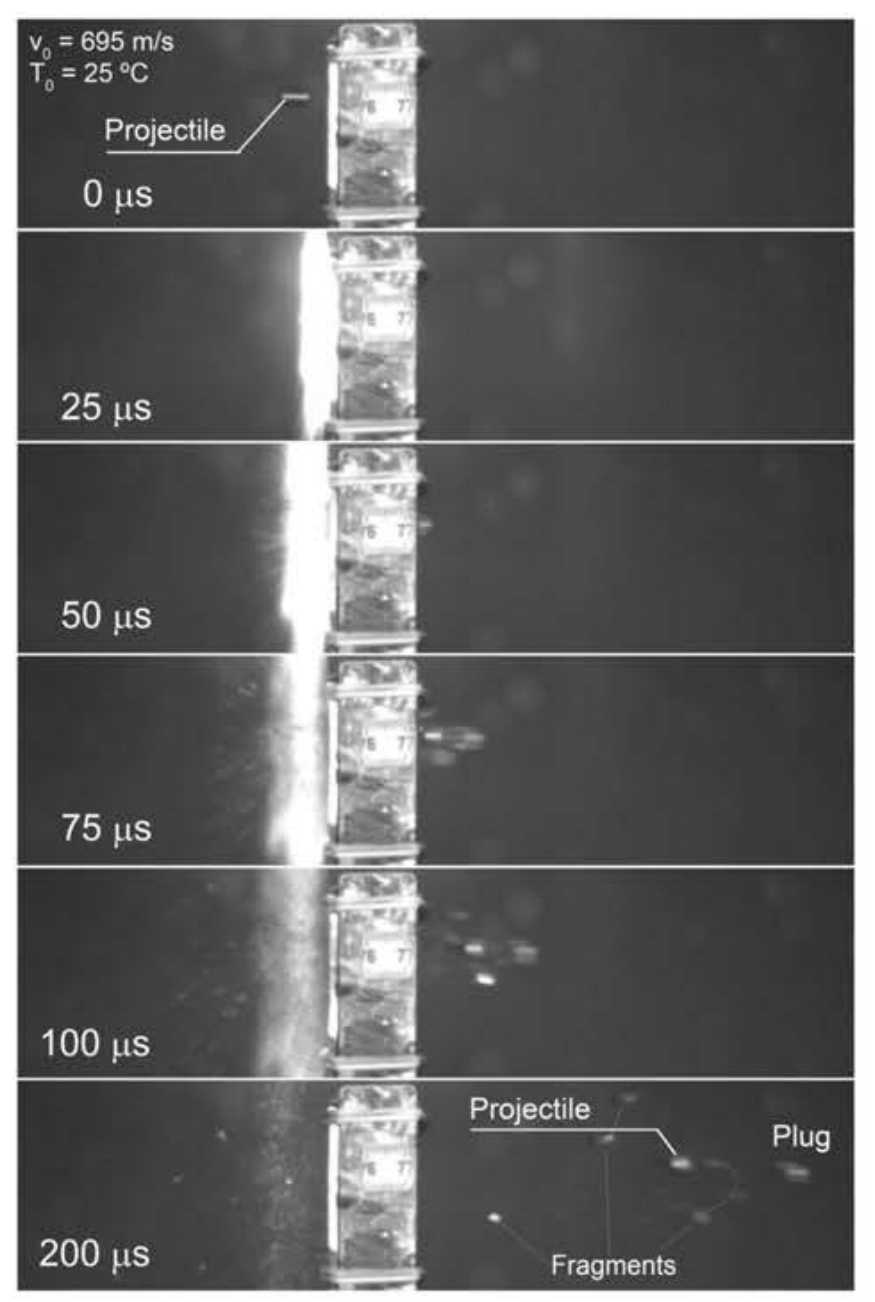

Fig. 3. High-speed video image sequence corresponding to an impact test with initial velocity of $695 \mathrm{~m} / \mathrm{s}$ performed at room temperature.

\section{Computational material model}

The model employed to carry out the present investigation, implemented in LS-DYNA [11] non-linear finite element code, is described in this section. The model was designated as JohnsonCook-Xue-damage (JCXd) to distinguish it from the uncoupled version JCX, postulated by Chocron et al. [17].

\subsection{Constitutive equations}

Assuming the additive decomposition of the strain tensor as:

$\varepsilon=\varepsilon^{e}+\varepsilon^{p}$

the coupled elastic-damaged law reads:

\section{Table 2}

Recht-Ipson model fit for the experimental and numerical data at $25^{\circ} \mathrm{C}, 400^{\circ} \mathrm{C}$ and $700{ }^{\circ} \mathrm{C}$.

\begin{tabular}{|c|c|c|c|c|c|c|}
\hline \multirow[t]{2}{*}{ Temperature $\left({ }^{\circ} \mathrm{C}\right)$} & \multicolumn{3}{|c|}{ Experiments } & \multicolumn{3}{|c|}{ Numerical simulations } \\
\hline & $v_{b l}(m / s)$ & $a(m / s)$ & $p$ & $v_{b l}(m / s)$ & $a(m / s)$ & $p$ \\
\hline 25 & 365 & 0.81 & 4.60 & 419 & 0.79 & 4.00 \\
\hline 400 & 355 & 0.79 & 2.70 & 355 & 0.79 & 3.10 \\
\hline 700 & 320 & 0.76 & 4.60 & 350 & 0.76 & 4.60 \\
\hline
\end{tabular}

$\sigma=w(D) C: \varepsilon^{e}=w(D) C:\left(\varepsilon-\varepsilon^{p}\right)$

The weakening function $w(D)$ defined as follows:

$w(D)=1-D^{\beta}$

where $D$ is the damage parameter and $\beta$ is the weakening exponent $C$ is the fourth-order isotropic tensor of elastic moduli given by:

$C=\frac{\nu E}{(1+\nu)(1-2 v)} I \otimes I+\frac{E}{(1+\nu)} I$

where $E$ is the elastic modulus and $\nu$ is the Poisson's ratio.

A von Mises yield function was chosen to model the plastic flow, ensuring the convexity of the yield surface. For the JCXd material model the yield function reads:

$\phi\left(\sigma, Y^{\mathrm{JCXd}}\right)=\phi\left(J_{2}, \bar{\varepsilon}_{p}, \dot{\bar{\varepsilon}}_{p}, T, D\right)=\bar{\sigma}(\sigma)-Y^{\mathrm{JCXd}}\left(\bar{\varepsilon}_{p}, \dot{\bar{\varepsilon}}_{p}, T, D\right)$

where $\bar{\sigma}=\sqrt{3 J_{2}}=\sqrt{3 / 2 \sigma^{\prime}: \sigma^{\prime}}$ is the equivalent stress and $Y^{\mathrm{J} C \mathrm{Cx}}$ is the JCXd flow stress defined as:

$Y^{\mathrm{JCXd}}\left(\bar{\varepsilon}_{p}, \dot{\bar{\varepsilon}}_{p}, T, D\right)=w(D) Y_{M}\left(\bar{\varepsilon}_{p}, \dot{\bar{\varepsilon}}_{p}, T\right)$

where $Y_{M}$ represents the matrix material hardening. The hardening of the matrix material was modelled with a Johnson-Cook type relationship [10] as follows:

$Y_{M}=Y^{J C}\left(\bar{\varepsilon}_{p}, \dot{\bar{\varepsilon}}_{p}, T\right)=\left[A+B \bar{\varepsilon}_{p}^{n}\right]\left[1+C \ln \dot{\bar{\varepsilon}}_{p}^{*}\right]\left[1-T^{*} m\right]$

where $A B, n C$, and $m$ are material constants, $\dot{\bar{\varepsilon}}_{p}^{*}=\dot{\varepsilon}_{p} / \dot{\varepsilon}_{0}$ is the dimensionless plastic strain rate, $\dot{\varepsilon}_{0}$ is the reference strain rate $T^{*}=\left(T-T_{r}\right) /\left(T_{r}-T_{m}\right)$, is the homologous temperature $T$, is the current temperature $T_{r}$, is the room or reference temperature and $T_{m}$ is the melting temperature.

The associative flow rule chosen reads:

$\dot{\varepsilon}^{p}=\dot{\lambda} N\left(\sigma, Y^{\mathrm{JCXd}}\right)$

where $N$ is the flow vector given by:

$N\left(\sigma, \bar{\varepsilon}_{p}\right)=\frac{\partial \phi\left(\sigma, Y^{\mathrm{JCXd}}\right)}{\partial \sigma}$

\subsection{Failure criterion and evolution of the internal variables} is:

The set of internal variables [18] $\alpha$ chosen for the present model

$\alpha=\left\{\bar{\varepsilon}_{p}, D\right\}$

where $\bar{\varepsilon}_{p}$ is the equivalent plastic strain and $D$ is the damage parameter. The generalised hardening modulus [18] is then composed by:

$H=\left\{H_{1}, H_{2}\right\}$

The evolution law for the equivalent plastic strain is:

$\dot{\bar{\varepsilon}}_{p}=\dot{\lambda} ; H_{1}=1$

The damage evolution law, established by Johnson and Cook [9], may be described as follows: 

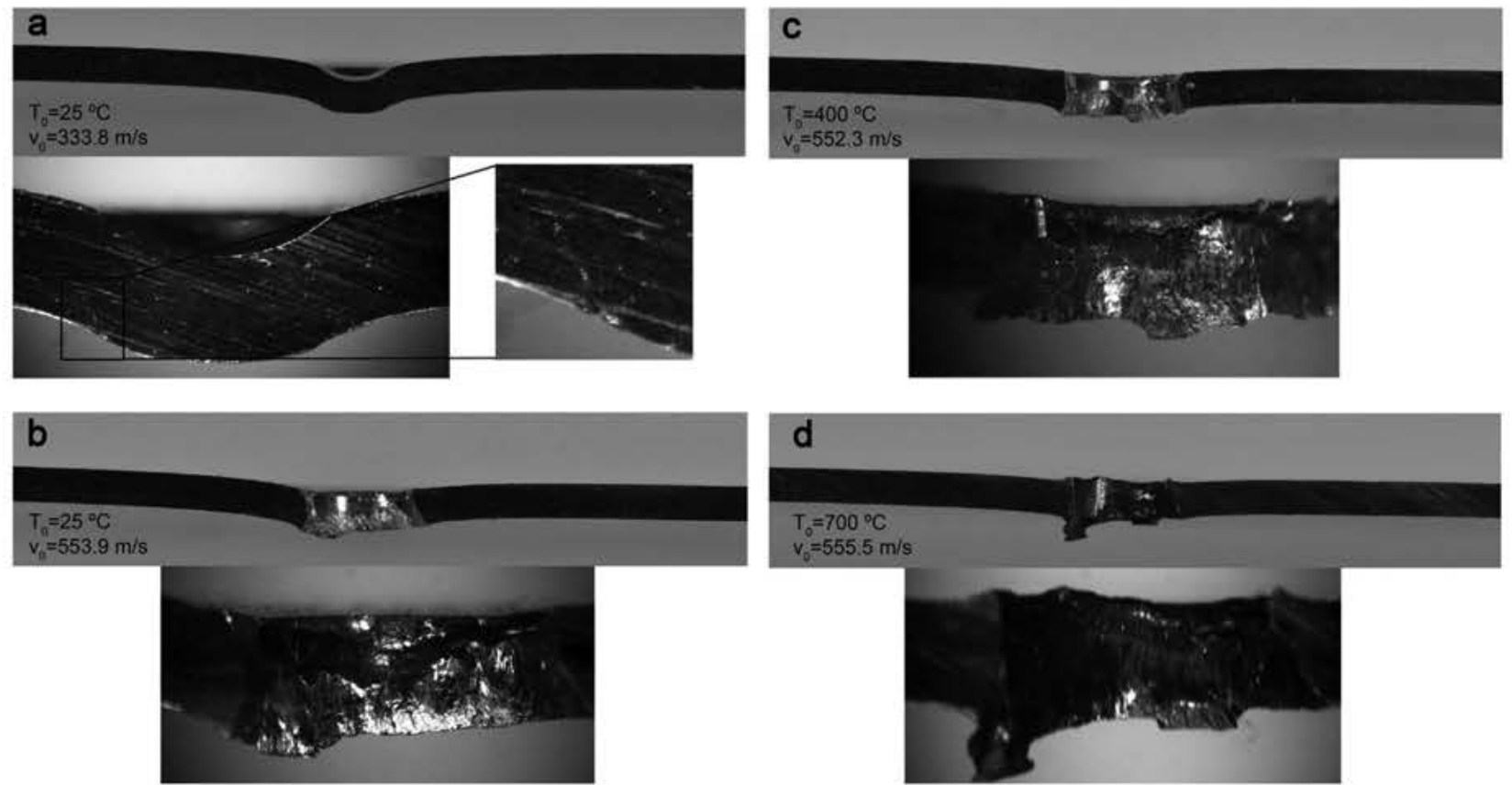

Fig. 4. (a) Non-perforated plate at room temperature. Perforated plates with similar initial velocities $v_{0} \sim 550 \mathrm{~m} / \mathrm{s}$ at $25{ }^{\circ} \mathrm{C}(\mathrm{b}), 400{ }^{\circ} \mathrm{C}(\mathrm{c})$ and $700{ }^{\circ} \mathrm{C}$ (d).

$\dot{D}=\dot{\lambda} H_{2}=\frac{1}{\bar{\varepsilon}_{p}^{f C X d}\left(\sigma^{*}, \dot{\bar{\varepsilon}}_{p}, T, \theta\right)} \dot{\bar{\varepsilon}}_{p} ; H_{2}=\frac{1}{\bar{\varepsilon}_{p}^{\mathrm{JCXd}}\left(\sigma^{*}, \dot{\bar{\varepsilon}}_{p}, T, \theta\right)}$

The elements are eroded when $D=1$.

The expression for the equivalent plastic strain to failure $\bar{\varepsilon}_{p}^{f} \mathrm{JCXd}$ is:

$\vec{\varepsilon}_{p}^{\mathrm{JCXd}}=\vec{\varepsilon}_{p}^{f J C} \mu_{\theta}(\theta)$

where $\mu_{\theta}$ is the second kind of the Lode angle dependent function $[8], \vec{\varepsilon}_{p}^{f J C}$ is the equivalent plastic strain of the Johnson-Cook failure criterion [9] given by:

$$
\begin{aligned}
\bar{\varepsilon}_{p}^{f J C}\left(\sigma^{*}, \dot{\bar{\varepsilon}}_{p}, T\right)= & {\left[D_{1}+D_{2} \exp \left(D_{3} \sigma^{*}\right)\right]\left[1+D_{4} \ln \dot{\bar{\varepsilon}}_{p}^{*}\right] } \\
& \times\left[1+D_{5} T^{*}\right]
\end{aligned}
$$

where $D_{1} D_{2}, D_{3} D_{4}$, and $D_{5}$ are material constants, $\sigma^{*}=\sigma_{H} / \bar{\sigma}$ is the stress triaxiality ratio. $\dot{\bar{\varepsilon}}_{p}^{*}$ and $T^{*}$ are identical as those variables previously defined. The second kind of Lode angle dependent function is defined as follows:

$\mu_{\theta}=\gamma+(1-\gamma)\left(\frac{6|\theta|}{\pi}\right)$

where $\gamma=\bar{\varepsilon}_{p}$ shear $/ f_{p}^{\text {tension or compression }}$ is the relative failure ratio between generalised shear and axisymmetric tension or compression stress states and $\theta=-(1 / 3) \sin ^{-1}\left(3 \sqrt{3} J_{3} / 2 J_{2}^{3 / 2}\right)=$ $-(1 / 3) \sin ^{-1}\left(27 \operatorname{det}\left(\sigma^{\prime}\right) / 2 \bar{\sigma}^{3}\right)$ is the Lode angle. The second kind of Lode angle dependent function leads to a symmetric failure surface with respect to the pure shear failure locus, as can be seen in Fig. 5.

The evolution law for the temperature is given by:
$\dot{T}=\frac{\chi}{\rho C_{p}} \sigma: \dot{\varepsilon}^{p}$

where $\chi$ is the Taylor-Quinney coefficient $\rho$, is the mass density and $C_{p}$ is the specific heat.

The expression of the plastic multiplier comes from the consistency condition $(\dot{\phi}=0)$. The consistency condition for the postulated yield function is:

$$
\begin{aligned}
\dot{\phi}= & \frac{\partial \phi}{\partial \sigma}: C:(\dot{\varepsilon}-\dot{\lambda} N)+\dot{\lambda} \frac{\partial \phi}{\partial \bar{\varepsilon}_{p}} H_{1}+\dot{\lambda} \frac{\partial \phi}{\partial D} H_{2}=\frac{\partial \phi}{\partial \sigma}: C:(\dot{\varepsilon}-\dot{\lambda} N) \\
& +\dot{\lambda}\left(\frac{\partial \phi}{\partial Y^{\mathrm{J} C X d}} \frac{\partial Y^{\mathrm{JCXd}}}{\partial \bar{\varepsilon}_{p}} H_{1}+\frac{\partial \phi}{\partial Y^{\mathrm{JCX} d}} \frac{\partial Y^{\mathrm{JCXd}}}{\partial w} \frac{\partial w}{\partial D} H_{2}\right) \\
& =\frac{\partial \phi}{\partial \sigma}: C:(\dot{\varepsilon}-\dot{\lambda} N)-\dot{\lambda}\left(w \frac{\partial Y_{M}}{\partial \bar{\varepsilon}_{p}} H_{1}-Y_{M} \frac{\partial W}{\partial D} H_{2}\right) \\
& =\frac{\partial \phi}{\partial \sigma}: C:(\dot{\varepsilon}-\dot{\lambda} N)-\dot{\lambda}\left(w H H_{1}-\beta D^{\beta-1} Y_{M} H_{2}\right)=0
\end{aligned}
$$

where $H$ is the hardening modulus of the matrix material $H=\partial Y_{M} / \partial \bar{\varepsilon}_{p}$. Operating in (19) the plastic multiplier can be obtained:

$\dot{\lambda}=\frac{\frac{\partial \phi}{\partial \sigma}: C: \dot{\varepsilon}}{\frac{\partial \phi}{\partial \sigma}: C: N+w H H_{1}-\beta D^{\beta-1} Y_{M} H_{2}}$

\subsection{Time integration algorithm}

An incremental form is required for solving the stress update of the rate constitutive equations of the elastoplastic problem exposed in the two previous sections. Since the solutions for complex loading paths are not known, an algorithm-type implementation for integrating the incremental constitutive equations in a known time interval is customarily adopted. The most common such approach is to adopt Euler-based schemes. The solution of 


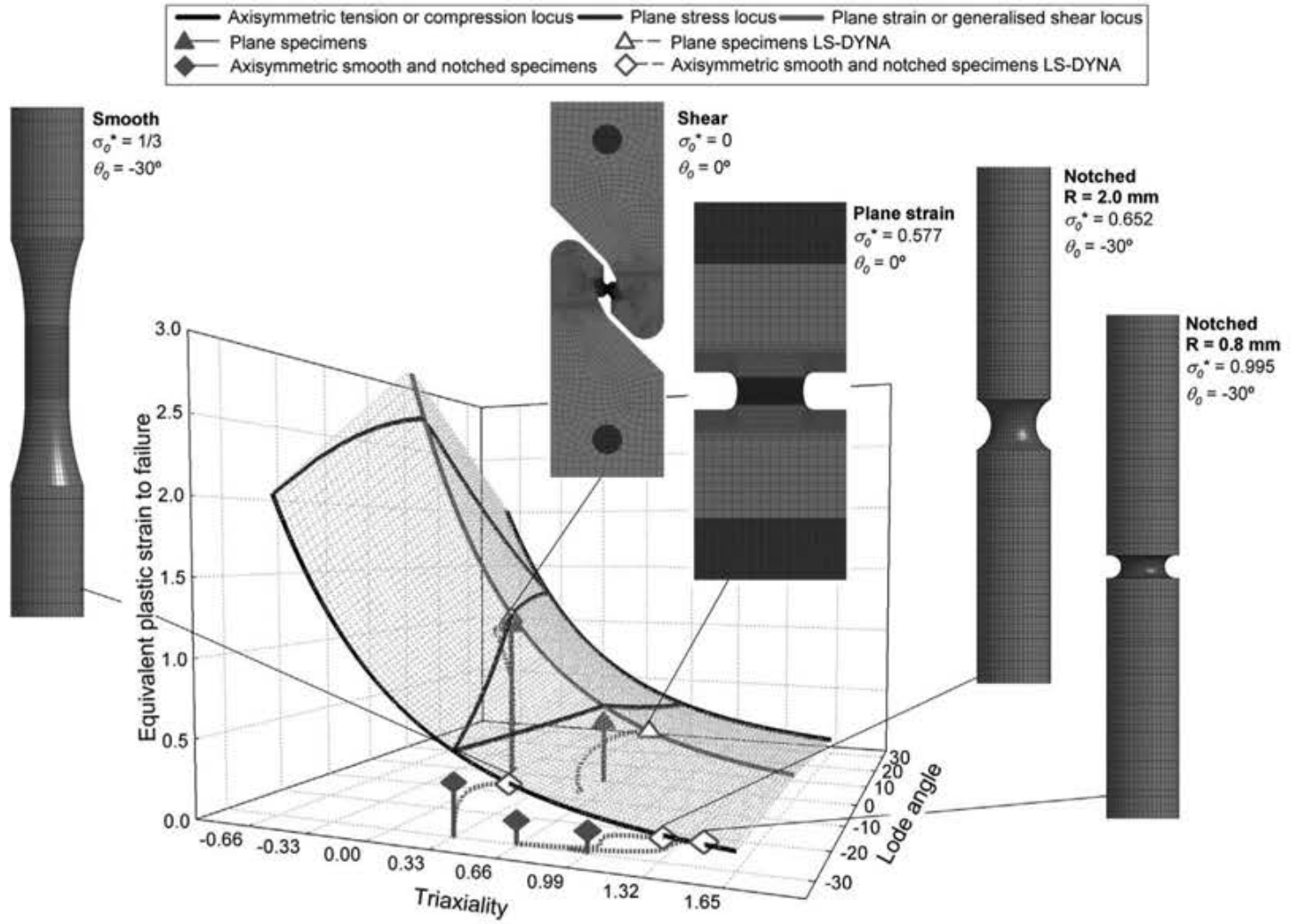

Fig. 5. Failure surface for a quasi-static loading case of the precipitation hardened Inconel 718 nickel-base superalloy. Finite element models employed for the numerical simulations with their corresponding initial triaxiality and Lode angle values. (For interpretation of the references to colour in this figure legend, the reader is referred to the web version of this article.)

these incremental elastoplastic equations when plastic loading occurs is the so-called return-mapping. In this case, a fully implicit backward Euler scheme [19] was adopted. It should be noted that the global time integration is explicit in this case. Therefore, the stiffness matrix does not have to be update.

Let us consider the constitutive equations for the postulated model:

$$
\begin{aligned}
& \sigma=w(D) C: \varepsilon^{e}=w(D) C:\left(\varepsilon-\varepsilon^{p}\right) \\
& \dot{\varepsilon}^{p}=\dot{\lambda}\left(\sigma, Y^{\mathrm{JCXd}}\right) \\
& \dot{\bar{\varepsilon}}_{p}=\dot{\lambda} \\
& \dot{D}=\frac{1}{\bar{\varepsilon}_{p}^{\mathrm{J} C X d}} \dot{\bar{\varepsilon}}_{p} \\
& \dot{\lambda} \geq 0, \quad 0 \leq \phi, \quad \dot{\lambda} \phi=0 \\
& \dot{\lambda}=\frac{\frac{\partial \phi}{\partial \sigma}: C: N+w H H_{1}-\beta D^{\beta-1} Y_{M} H_{2}}{\frac{\partial \phi}{d \sigma}: C: \dot{\varepsilon}} \\
& \dot{T}=\frac{\chi}{\rho C_{p}} \sigma: \dot{\varepsilon}^{p}
\end{aligned}
$$

The integration algorithm solves these set of equations for a prescribed strain increment $\Delta \varepsilon$ in a time increment $\Delta t=t_{n+1}-t_{n}$ for given $\varepsilon_{n}^{e}, \bar{\varepsilon}_{p n} D_{n}$, and $T_{n}$. The objective is to compute $\varepsilon_{n+1}^{e}, \bar{\varepsilon}_{p n+1}$ $D_{n+1}, T_{n+1}$ and $\Delta \lambda=\Delta t \lambda$ satisfying the loading/unloading conditions, where the stress is given by:

$$
\sigma_{n+1}=w_{n+1}\left(D_{n+1}\right) C: \varepsilon_{n+1}^{e}=w_{n+1}\left(D_{n+1}\right) C:\left(\varepsilon_{n+1}-\varepsilon_{n+1}^{p}\right)
$$

The backward Euler integration scheme for the set of equation (21) is:

$$
\begin{gathered}
\varepsilon_{n+1}^{e}=\varepsilon_{n}^{e}+\Delta \varepsilon-\Delta \lambda N_{n+1} \\
\bar{\varepsilon}_{p n+1}=\bar{\varepsilon}_{p n}+\Delta \lambda \\
\dot{\bar{\varepsilon}}_{p n+1}=\frac{\Delta \lambda}{\Delta t} \\
D_{n+1}=D_{n}+\Delta D=D_{n}+\Delta \lambda \frac{1}{\bar{e}_{p n+1}^{j c x d}} \\
\sigma_{n+1}=w_{n+1}\left(D_{n+1}\right) C: \varepsilon_{n+1}^{e}=w_{n+1}\left(D_{n+1}\right) C:\left(\varepsilon_{n+1}-\varepsilon_{n+1}^{p}\right) \\
T_{n+1}=T_{n}+\frac{\chi}{\rho C_{p}} \sigma_{n+1}: \Delta \varepsilon_{n+1}^{p} \\
\dot{\lambda} \geq 0, \quad 0 \leq \phi, \quad \dot{\lambda} \phi=0
\end{gathered}
$$

The well-known two-step elastic predictor/plastic corrector algorithm is used to solve the equations above. It should be noted that for the sake of simplicity the temperature update is performed in an explicit way (forward Euler). The first step is a trial elastic step in which $\Delta \lambda=0$ is assumed. The trial elastic step assumes the following: 


$$
\begin{gathered}
\varepsilon_{n+1}^{e \text { trial }}=\varepsilon_{n}^{e}+\Delta \varepsilon \\
\bar{\varepsilon}_{p n+1}^{\text {trial }}=\bar{\varepsilon}_{p n} \\
\dot{\bar{\varepsilon}}_{p n+1}^{\text {trial }}=\dot{\bar{\varepsilon}}_{p n} \\
D_{n+1}^{\text {trial }}=D_{n} \\
\sigma_{n+1}^{\text {trial }}=w_{n+1}^{\text {trial }}\left(D_{n+1}^{\text {trial }}\right) C: \varepsilon_{n+1}^{e \text { trial }} \\
T_{n+1}=T_{0}
\end{gathered}
$$

If the solution assumed by trial step lies inside the yield surface, i.e., $\phi\left(\sigma_{n+1}^{\text {trial }}, Y_{n+1}^{\mathrm{JCXd} \text { trial }}\right) \leq 0$, then the variables will be updated as $(\cdot)_{n+1}=(\cdot)_{n+1}^{\text {trial }}$. Otherwise, the plastic corrector step or returnmapping is necessary. The plastic corrector returns from trial state to the yield surface giving the updated state $n+1$. The set of implicit equations in the updated state is:

$$
\begin{gathered}
\varepsilon_{n+1}^{e}=\varepsilon_{n+1}^{e \text { trial }}+\Delta \varepsilon-\Delta \lambda N_{n+1} \\
\bar{\varepsilon}_{p n+1}=\bar{\varepsilon}_{p n+1}^{\text {trial }}+\Delta \lambda \\
\dot{\bar{\varepsilon}}_{p n+1}=\frac{\Delta \lambda}{\Delta t} \\
D_{n+1}=D_{n+1}^{\text {trial }}+\Delta D=D_{n+1}^{\text {trial }}+\Delta \lambda \frac{1}{\bar{\varepsilon}_{p n+1}^{j \text { cxd }}} \\
\phi\left(\sigma_{n+1}, Y_{n+1}^{\mathrm{JCXd}}\right)=0 \\
\sigma_{n+1}=w_{n+1}\left(D_{n+1}\right) C: \varepsilon_{n+1}^{e}=w_{n+1}\left(D_{n+1}\right) C:\left(\varepsilon_{n+1}-\varepsilon_{n+1}^{p}\right) \\
T_{n+1}=T_{n}+\frac{\chi}{\rho C_{p}} \sigma_{n+1}: \Delta \varepsilon_{n+1}^{p}
\end{gathered}
$$

Many strategies can be adopted to solve the equation system (25). The selection of the elastic predictor/plastic corrector algorithm depends on the complexity of the constitutive equations formulated and the finite element code chosen for implementation. Here, a two equation system with $\Delta \lambda=\Delta \bar{\varepsilon}_{p}$ and $D$ as unknowns has been solved with a Newton-Raphson algorithm.

\subsection{Model calibration}

The experimental campaign carried out to calibrate the Inconel 718 precipitation hardened superalloy included the following tests:

- Quasi-static tensile tests of axisymmetric smooth and notched specimens at room temperature

- Dynamic tensile tests of axisymmetric specimens at various temperatures $\left(25^{\circ} \mathrm{C}-800^{\circ} \mathrm{C}\right)$

- Quasi-static tensile tests of shear and plane strain specimens at room temperature

The quasi-static tests were conducted using a screw-driven universal testing machine. The strain in the axisymmetric specimens was calculated monitoring the minimum cross-section diameter obtained with a laser micrometer. Conversely, the strain from the plane specimens was computed with an in-house DIC system developed by Fagerholt et al. [20]. The zones of the specimens that presented the largest plastic strain to failure were used for such a purpose. The dynamic tests were carried out using a Split Hopkinson Tension Bar (SHTB). The dimensions, geometry and configuration of the SHTB are specified in [7]. The specimen strains in this case were calculated from the readings that the strain gauges attached to the input and output bars gave.

Since the JCXd model has coupled relationships, the calibration procedure was necessarily iterative. Previous studies [21-25] have used direct or inverse calibration methods to obtain the fracture surface using the triaxiality. Lode angle and equivalent plastic strain histories collected from numerical simulations, considering therefore the whole stress state evolution up to failure. Therefore, all the tests were simulated to obtain the triaxility. Lode angle and equivalent plastic strain histories. In the simulations of the axisymmetric specimens, the triaxiality and Lode angle histories were collected from the centre of the specimens, while the equivalent plastic strain histories were computed using the minimum cross-section diameter $d$ as $\bar{\varepsilon}_{p}=2 \ln \left(d_{0} / d\right)$. The triaxiality, Lode angle and equivalent plastic strain histories of the plane strain specimens were taken from elements that were located close from where the DIC measurements were made. However, the specimens failed first in the interior. Therefore, the parameter histories were collected not from the specimen surface but from the interior.

In Fig. 5, the solid lines represent constant initial triaxiality and Lode angle values, whereas the solid green points correspond to the experimental equivalent plastic strain to failure. The evolution of the equivalent plastic strain as a function of the triaxility and the Lode angle until failure computed from the numerical simulations can be observed in green dashed curves in Fig. 5. The failure strain is marked with hollow green points. More details on the calibration procedure necessary to characterise the precipitation hardened Inconel 718 nickel-base can be found in $[7,26]$. The model constants are summarised in Table 3.

\section{Failure under quasi-static loadings}

\subsection{Numerical models}

The fracture pattern predictability of the postulated JCXd model was assessed for quasi-static loadings. For such a purpose two reference mechanical tests were taken as basis: (i) a tensile test of an axisymmetric smooth specimen and (ii) a tensile test of a plane strain specimen. Cup-cone and slanted fracture patterns for tests (i) and (ii) were respectively observed in the mechanical tests $[7,26]$. The influence of the mesh size and the $\gamma$ parameter on the fracture pattern prediction was analysed.

The calibrated symmetric JCXd failure surface for the precipitation hardened Inconel 718 alloy is depicted in Fig. 5 in the $\vec{\varepsilon}_{p}^{f}, \sigma^{*}, \theta$

\begin{tabular}{|c|c|c|c|c|c|c|c|}
\hline \multicolumn{8}{|c|}{ Isotropic elastic constants, physical properties and weakening exponent } \\
\hline$E(\mathrm{GPa})$ & $v$ & \multicolumn{2}{|c|}{$\rho\left(\mathrm{kg} / \mathrm{m}^{3}\right)$} & $C_{p}\left(\mathrm{~J} / \mathrm{kg}^{\circ} \mathrm{C}\right)$ & \multicolumn{2}{|c|}{$\chi$} & $\beta$ \\
\hline 185 & 0.33 & \multicolumn{2}{|c|}{8190} & 435 & \multicolumn{2}{|c|}{0.9} & 6.00 \\
\hline \multicolumn{8}{|c|}{ Constitutive relation } \\
\hline \multicolumn{3}{|c|}{ Strain hardening } & \multicolumn{2}{|c|}{ Strain rate hardening } & \multicolumn{3}{|c|}{ Thermal softening } \\
\hline$A(\mathrm{MPa})$ & $B(\mathrm{MPa})$ & $n$ & $\mathrm{C}$ & $\dot{\varepsilon}_{0}\left(\mathrm{~s}^{-1}\right)$ & $m$ & $T_{r}\left({ }^{\circ} \mathrm{C}\right)$ & $T_{m}\left({ }^{\circ} \mathrm{C}\right)$ \\
\hline 1200 & 1284 & 0.54 & 0.006 & $1.0 \times 10^{-3}$ & 1.20 & 25 & 1800 \\
\hline \multicolumn{8}{|c|}{ Failure criterion } \\
\hline$D_{1}$ & $D_{2}$ & $D_{3}$ & & $D_{4}$ & & $\gamma_{F}$ & $A R_{c}$ \\
\hline 0.04 & 0.75 & -1 & 45 & 0.04 & & 1.50 & 0.99 \\
\hline
\end{tabular}
space [7]. The figure shows the initial triaxiality and Lode angle values for all the tested specimens in solid green lines. The history of such parameters gathered from the numerical simulations performed using the JCXd material constants (see Table 3) are plotted in dashed green lines.

The axisymmetric specimens were modelled employing eightnode reduced-integration elements with stiffness-based hourglass control elements available in LS-DYNA [11]. The geometry and dimensions of the specimens modelled can be seen in Fig. 6. Even

Table 3

JCXd material constants for precipitation hardened Inconel 718 nickel-base superalloy. 
though, 2D axisymmetric models of such type of specimens have been previously used to perform similar studies with damagebased Gurson-like models [13,27], the axial symmetry introduces additional restrictions on the degrees of freedom that forces the crack to be axisymmetric. A full 3D finite element modelling was considered to be more efficient in predicting the real fracture process. It should be noted that occasionally the element sizes used to predict correctly the fracture patterns require being extremely small. Therefore, 2D axisymmetric models are the only possible way to carry out numerical simulations within reasonable computer calculation times.

A quasi-static loading was simulated applying a prescribed displacement to the nodes of one end of the specimen, while the degree of freedom in the load-axis direction of the opposite end nodes was constrained. The displacement was applied ensuring quasi-static loading conditions. To ensure that no undesired effects were introduced in the models, the thermal softening dependency was deactivated from the model setting $\chi=0.0$. A model with 44 elements across the diameter was selected to obtain the true stress-strain curves. The result is plotted and compared with the experimental data in Fig. 7. The numerical true stress-plastic strain curve as well as the strain to failure, marked with a blue arrow, were in good agreement with the experimental data.

A full 3D finite element model, without additional symmetries, was employed to simulate the slant fracture of the plane strain specimens. The same element type of that used for the modelling of the axisymmetric specimen was used to discretise the plane strain specimen. In order to simulate the clamps of the universal testing machine, the part of the specimen clamped was modelled as a rigid material. Such parts are shown in blue in the finite element models for plane strain specimens depicted in Fig. 8. The prescribed boundary condition was applied in terms of displacement on the upper rigid body simulating the testing machine actuator movement. Conversely, the movement of the lower rigid body was constrained in all directions. The displacement on the upper rigid body was applied ensuring that quasi-static loading conditions were met. A numerical simulation with 8 elements across the thickness was carried out as reference.
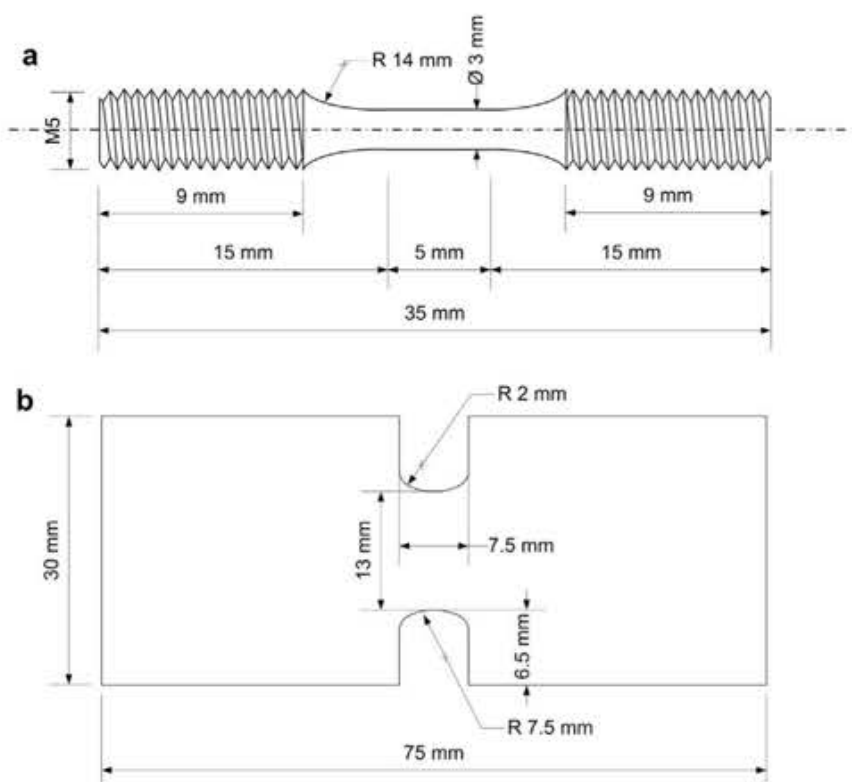

Fig. 6. Geometry and dimensions of the smooth axisymmetric (a) and the plane strain (b) specimens.

\subsection{Mesh size dependence}

Even though the numerical simulations performed with the coarsest meshes, 44 elements across the diameter for the axisymmetric specimen and 8 elements across the thickness for the plane strain specimen, were able to predict with relative accuracy the elastoplastic behaviour and failure points of the experimental tests, the failure patterns that one might expect were not observed in such simulations. Previous studies have pointed out the importance of the mesh size for the prediction of fracture patterns under quasistatic loadings $[5,13]$. Therefore, three different mesh sizes were used for the current study. The objective of modifying the mesh size was not to compare the stress-strain curves but to observe the capability of the material model to predict the fracture patterns.

The expected fracture pattern for the plane strain specimen was slanted fracture across the thickness. Therefore, the mesh size was modified only across the thickness. Three mesh sizes, 8,16 and 32 elements across the thickness, were used to perform the same numerical simulation (see the top of Fig. 8(a)). In order to analyse the fracture process, the finite element models were cut along the $\mathrm{xz}$ symmetry plane and the damage contour plots depicted for the three mesh sizes (see bottom of Fig. 8(a)). At the bottom of Fig. 8(a), from left to right, the fracture of the specimens with 8,16 and 32 elements can be seen. The first and second figures, 8 and 16 elements across the thickness, show a completely flat fracture surface. Nevertheless, observing the contours an $\mathrm{x}$-like damage localisation can be seen. Such a localisation leads to a slanted fracture surface if the mesh size is small enough as shows the third figure with 32 elements across the thickness. The mesh size effect in predicting the slant fracture has been previously addressed by Li and Wierzbicki [28]. They obtained very similar results on plane strain fracture.

The typical cup-cone fracture for ductile metals was expected for the numerical simulation performed on the axisymmetric specimen. In this case the mesh size was modified across the diameter and only in the gauge area. The specimen was then discretised employing 44,72 and 144 elements across the diameter as

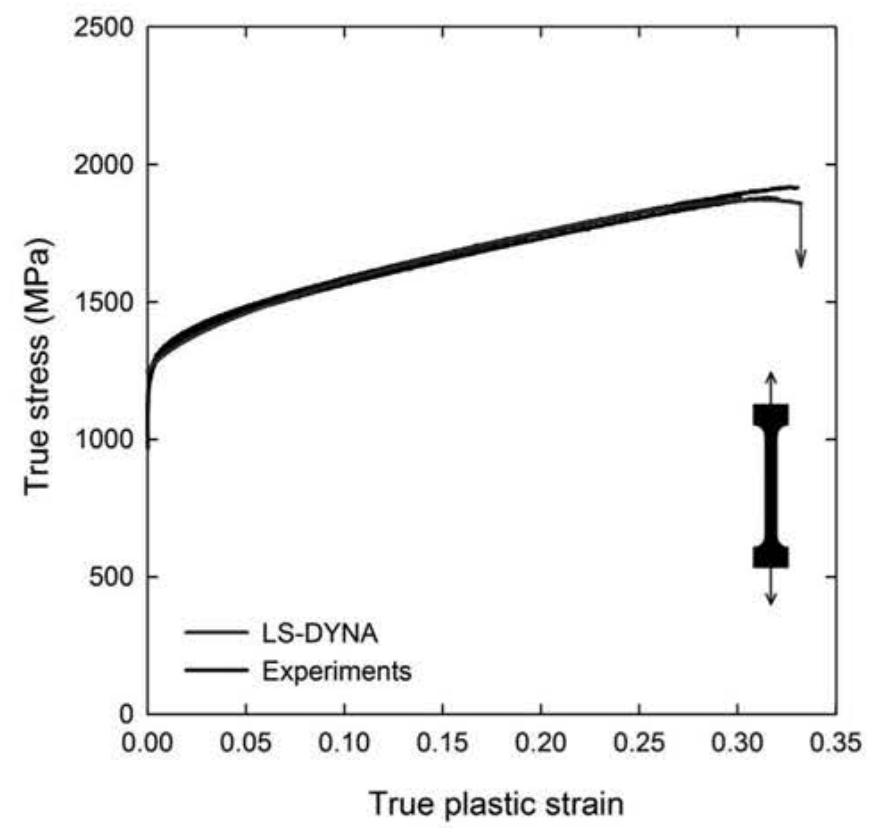

Fig. 7. True stress-plastic strain curves obtained from quasi-static tensile tests. (For interpretation of the references to colour in this figure legend, the reader is referred to the web version of this article.) 


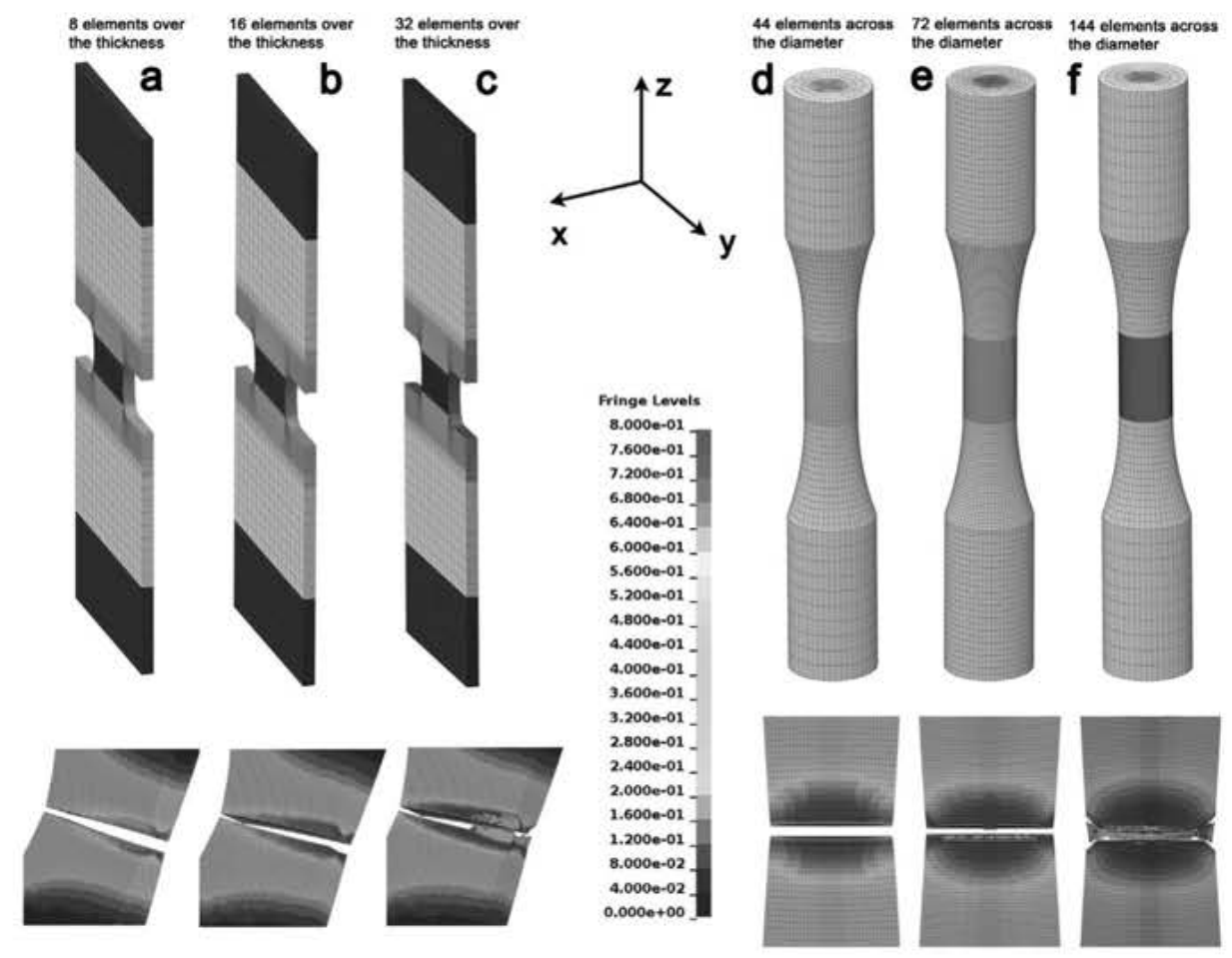

Fig. 8. (Top) Plane strain specimen finite element models with 8 (a), 16 (b) and 32 (c) elements over the thickness and axisymmetric smooth specimen models with 44 (d), 72 (e) and 144 (f) elements across the diameter. (Bottom) Failure patterns corresponding to the numerical simulations performed with the JCXd model and the meshes depicted in the top. (For interpretation of the references to colour in this figure legend, the reader is referred to the web version of this article.)

it is depicted at the top of Fig. 8(b) from left to right respectively. The pictures shown at the bottom of Fig. 8 (b) correspond to vertical $\mathrm{xz}$ cuts of the specimens. A flat fracture surface is the result of employing a discretisation of 44 elements across the diameter as one can observe on the first figure starting from the left. The next mesh size, 72 elements across the diameter, was not more successful in predicting the cup-cone fracture. Even though, the damage contours indicated that a change in the fracture mode, from mode I in the centre of the specimen to mode II near the surface of it, might occur. In the next figure the specimen was discretised with 144 elements across the diameter and as expected, a change in the fracture mode led to cup-cone fracture.

\subsection{Weakening and Lode angle dependency}

Once the mesh size to obtain the desired fracture patterns was established, the effect of the weakened constitutive equations and the Lode angle was studied. The main goal with this parametric study was to check the effect of the changes or the relative weight that such parameter may had on the fracture pattern prediction. Three cases were run for both axisymmetric and plane strain specimens:

(i) Regular uncoupled Johnson-Cook material model. This implies, according to equations ( 3 ) and (7) that the weakening exponent must be $\beta=\infty$ (see equation (4)). Additionally, to remove the Lode angle dependency from the failure criterion the $\gamma$ parameter was set to $\gamma=1.0$ (see equation (17)).

(ii) Johnson-Cook uncoupled model with Lode angle dependent failure criterion. The weakening exponent is $\beta=\infty$, whereas the $\gamma$ parameter was set to the calibrated value $\gamma=1.5$ (see Table 3).

(iii) JCXd coupled material model for the calibrated values $\beta=6.0$ : and $\gamma=1.5$ (see Table 3).
The results obtained for the axisymmetric specimen discretised with 144 elements across the diameter for the three cases (i), (ii) and (iii) described above are plotted in Fig. 9 (a)-(c) respectively. In the figures, damage contour plots are depicted from 0 to 1 . The upper part of the specimens was cut in half and removed in order to check the damage evolution of the internal elements. For the case (i) an almost flat fracture surface was observed, while for the case (ii) some change in the fracture mode could be noticed, but definitely not enough to consider it a cup-cone fracture. The case (iii) showed, in contrast to the other two cases, a successful cup-cone fracture.

Similarly to the above-described simulations, the plane strain specimen was simulated employing 32 element across the thickness for the three cases (i), (ii) and (iii) in Fig. 10 (a)-(c) respectively. The upper parts were also cut in half and damage contours are shown in all the plots. For the present case, the cases (i) and (ii) gave identical fracture patterns, i.e. flat surface. The simulation ran with the JCXd material model, case (iii), was the only successful case in predicting the slanted fracture of the plane strain specimen.

\section{Failure under impact loadings}

\subsection{Numerical model}

The finite element models for the plates were build following the specifications of the experimental set-up described previously. Both plate and projectile were modelled employing volume weighted four-node one-integration-point 2D axisymmetric elements with and stiffness-based hourglass control [29]. As is going to be exposed further in the article, the impacted zone was meshed with five mesh sizes. All of them were coarsened from the impact zone towards the clamped end using mesh transitions.

Since almost no deformation was observed in the projectiles after the plates were impacted, they were considered as rigid 

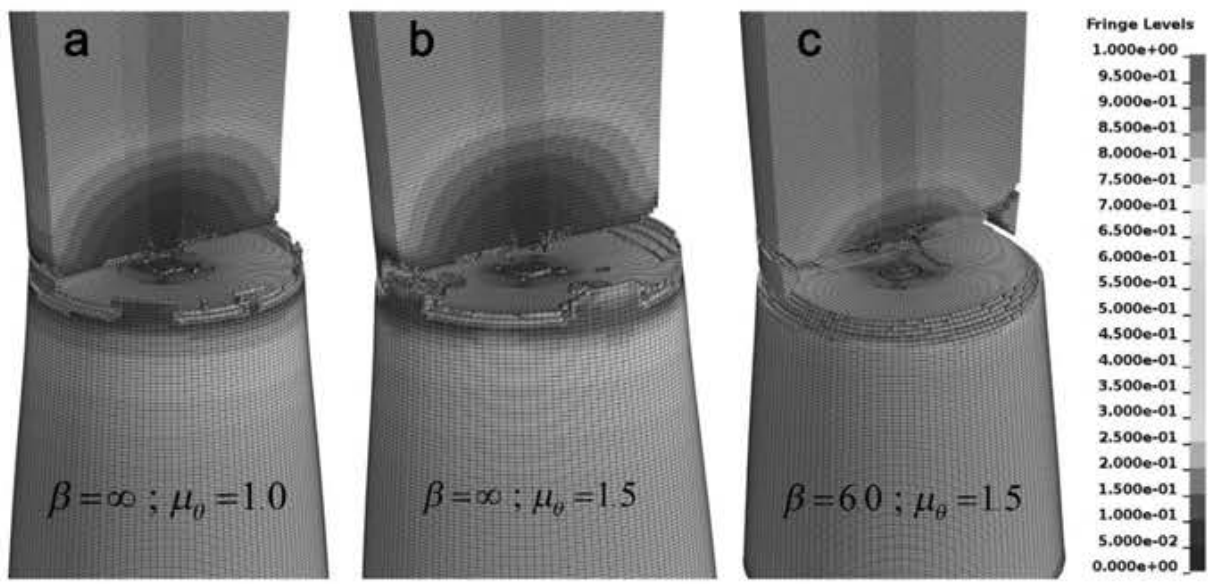

Fig. 9. Failure patterns obtained from the numerical simulation of the tensile test with 144 elements across the diameter. The three cases run were: regular JC (a), JCXd without weakening (b) and JCXd (c).

material and modelled consequently with "MAT_RIGID command [11]. The elastic modulus of the projectile was $E=210 \mathrm{GPa}$ and the Poisson's ratio $v=0.3$, while the density was set to $\rho=7850 \mathrm{~kg} / \mathrm{m}^{3}$. The calibrated constants for the JCXd material model for the Inconel 718 precipitation hardened nickel-base superalloy (see Table 3) were used for the plate. The temperature of the plates was simulated setting the $T_{0}$ parameter to $25^{\circ} \mathrm{C}, 400{ }^{\circ} \mathrm{C}$ or $700{ }^{\circ} \mathrm{C}$. Therefore, the temperature increase due to the adiabatic heating was computed explicitly starting from such $T_{0}$ temperatures (see set of equation (25)). The movement of the plate end nodes was constrained in all directions in order to simulate the clamps that hold the target firmly to the testing frame. The initial velocity of the projectile was modelled imposing an initial velocity to all its nodes. The contact between projectile and plate was simulated employing the *CONTACT_2D_AUTOMATIC_SINGLE_SURFACE penalty formulation algorithm available in LS-DYNA [11]. The friction between parts was set to zero, assuming that such a parameter does not play a significant role in the plate impact [30].

\subsection{Additional failure criterion}

The shell element time step in LS-DYNA is computed as the minimum of all the time steps computed for the entire model. The time step is computed as follows [29]:

$\Delta t_{e}=\frac{L_{s}}{c}$

where $L_{S}$ is the characteristic length of the element and $c=\sqrt{E / \rho(1-v)}$ is the elastic wave speed in the material. The default characteristic length for a quadrilateral element is given by [29]:

$L_{s}=\frac{A_{s}}{\max \left(L_{i}\right)}$

where $A_{s}$ is the area of the element and $L_{i}(i=1,2,3,4)$ is the length of the sides that define the element. At high impact velocities the elements of the target that are in contact with projectile are subjected to massive compression stresses. The combination of such stresses and a severe thermal softening effect makes cause extreme element distortions. The element straining provokes a dramatic decrease of the characteristic length and consequently a drop in the time step. Therefore, the calculations are slowed down and eventually terminated by the code due to the ridiculous low time steps.
Two approaches are usually proposed to solve such an issue in explicit numerical codes: the adaptive re-meshing and the element erosion [31]. The former was analysed by Børvik et al. [32], while the latter was reported on [33]. The element erosion in most of the cases is based on the time step, i.e., the elements are eroded when a critical time step is reached. Although it is valid and useful, until very low time steps are reached the elements are not eroded, which leads again to large computation times. Here, a geometricallybased additional criterion is proposed.

A quadrilateral element is sketched in its undeformed and deformed configuration in Fig. 11. The interior angles $\alpha_{i}(i=1,2,3,4)$ of the quadrilateral are computed during the calculation. When the two opposite angles reach a value close enough to $180^{\circ}$ the element is eroded. The criterion may be written as:

$$
\begin{aligned}
\left(\left|\cos \alpha_{1}\right|\right. & \left.=A R_{c} \text { and }\left|\cos \alpha_{3}\right|=A R_{c}\right) \text { or }\left(\left|\cos \alpha_{2}\right|\right. \\
& \left.=A R_{c} \text { and }\left|\cos \alpha_{4}\right|=A R_{c}\right) \Rightarrow \sigma=0
\end{aligned}
$$

where $A R_{c}$ is the critical aspect ratio value for which the elements are eroded. The residual velocity readings should be checked to ensure that there are no alterations in the simulations performed with and without the erosion criterion. Similar geometrically-based element erosion criterion was successfully applied on numerical simulations of plate impacts by Kane et al. [34].

\subsection{Mesh size dependence}

Previous studies highlighted the vital importance of the mesh size in numerical studies on the behaviour of plates under impact $[31,35]$. Furthermore, it seems that the residual velocity predictions always converge to a certain value when the mesh size is decreased [36]. Five mesh sizes were used to investigate the effect of it on residual velocity predictions: $64,96,128,192$ and 256 elements across the $1.6 \mathrm{~mm}$ thickness plates. The numerical study was performed only for the case of plate impacts at room temperature.

The mesh convergence study was carried out computing first the ballistic limit for the coarsest mesh ( 64 elements across the thickness or $31.25 \times 31.25 \mu \mathrm{m}^{2}$ element). The ballistic limit was found to be $525 \mathrm{~m} / \mathrm{s}$ (see Fig. 12). The computed ballistic limit velocity was used as initial velocity for the rest of the models with different mesh sizes. The plug residual velocities obtained from the simulations with different meshes are plotted in Fig. 12 in form of blue solid triangles. As expected, the residual velocity converged towards a unique value. The plug residual velocity history readings 


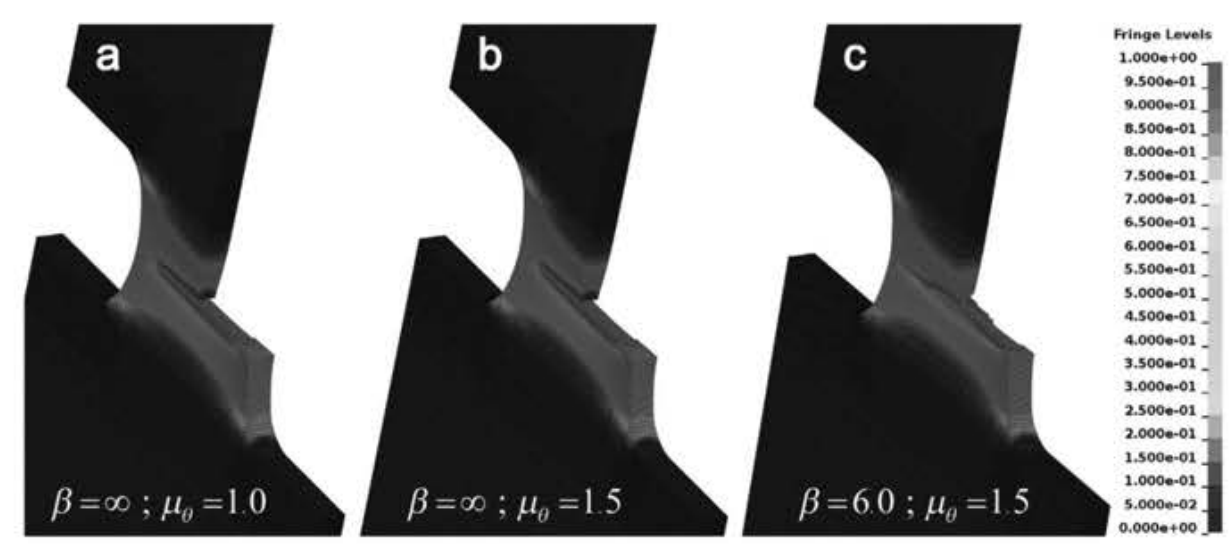

Fig. 10. Failure patterns obtained from the numerical simulation of the plane strain specimen with 32 elements over the thickness. The three cases run were: regular JC (a), JCXd without weakening (b) and JCXd (c).
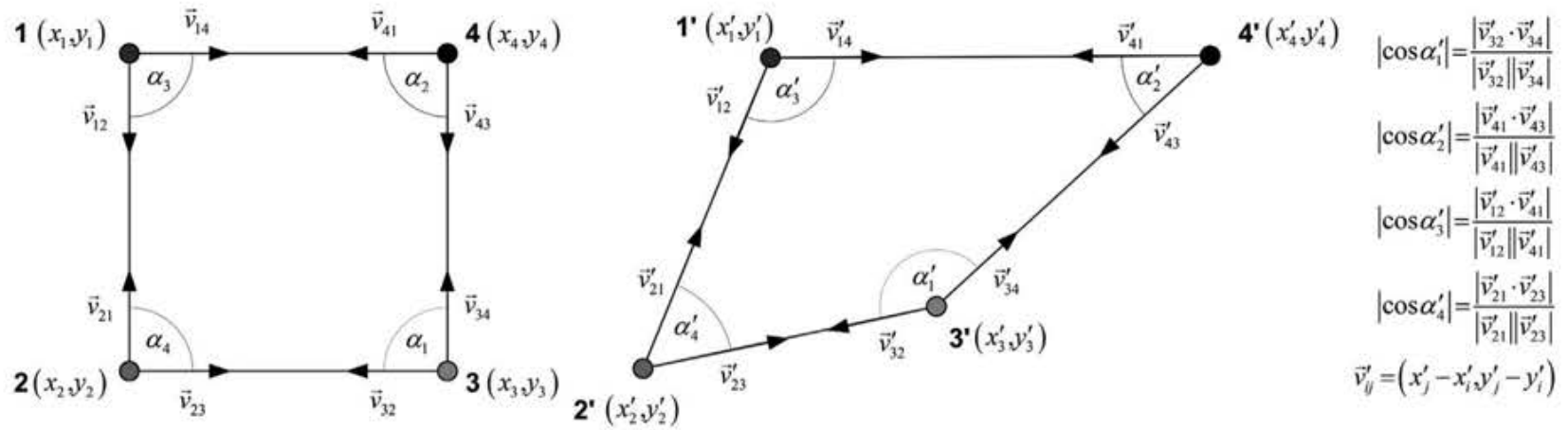

Fig. 11. Sketch of a quadrilateral element in undeformed (left) and deformed (right) configurations.

are plotted at the bottom of Fig. 13 for all the mesh sizes. The ballistic limit was then estimated introducing the residual velocity obtained from the simulations and the constants calculated from the experimental tests (see Table 2) for the modified version of the Recht-Ipson model in the equation (1):

$v_{b l}^{p}=\left[v_{0}^{p}-\left(\frac{v_{r}}{a}\right)^{p}\right]^{\frac{1}{p}}$

in which $v_{0}=525 \mathrm{~m} / \mathrm{s} a=0.81 \mathrm{~m} / \mathrm{s}$ and $p=4.60$. The results are depicted in Fig. 12 in form of hollow red circles. Finally, the ballistic limit was computed using the estimated values as starting initial velocities. Again, the ballistic limit converged to a value around $419 \mathrm{~m} / \mathrm{s}$. The results gathered in Fig. 12 suggested that a mesh size of 192 elements across the thickness was accurate enough to represent the plate behaviour correctly. The results presented here are in accordance with the reported by Kane et al. [35]. Fig. 12 reveals the strong role that the mesh size plays in plugging phenomena of plate impact simulations.

The selected mesh, 192 elements across the plate thickness, led to a mesh size of $\sim 10 \times 10 \mu \mathrm{m}^{2}$. DeMange et al. [16] reported shear band widths on Inconel 718 of the same order. As described previously, the main plugging failure mechanism on impacted plates is shear failure. Therefore, if the mesh size is not of the same order of the shear band width, the simulations will not be able to predict the mechanism responsible of the plate failure. Hence, the numerical residual velocity readings will not be in accordance with the experimental ones. Fig. 13 shows the influence of the mesh size, depicted at the top of the figure, on the shear band formation. Selecting such a small element size imposes a very small step time.
If it is small enough, the loss of ellipticity can be avoided according to Benallal et al. [37]. Thus, the problem will no more depend on the spatial discretisation.

The numerical simulations, showing temperature contours, performed with the $\sim 10 \times 10 \mu \mathrm{m}^{2}$ element size in the impact zone for the three temperatures, $25^{\circ} \mathrm{C}, 400{ }^{\circ} \mathrm{C}$ and $700{ }^{\circ} \mathrm{C}$ are shown in

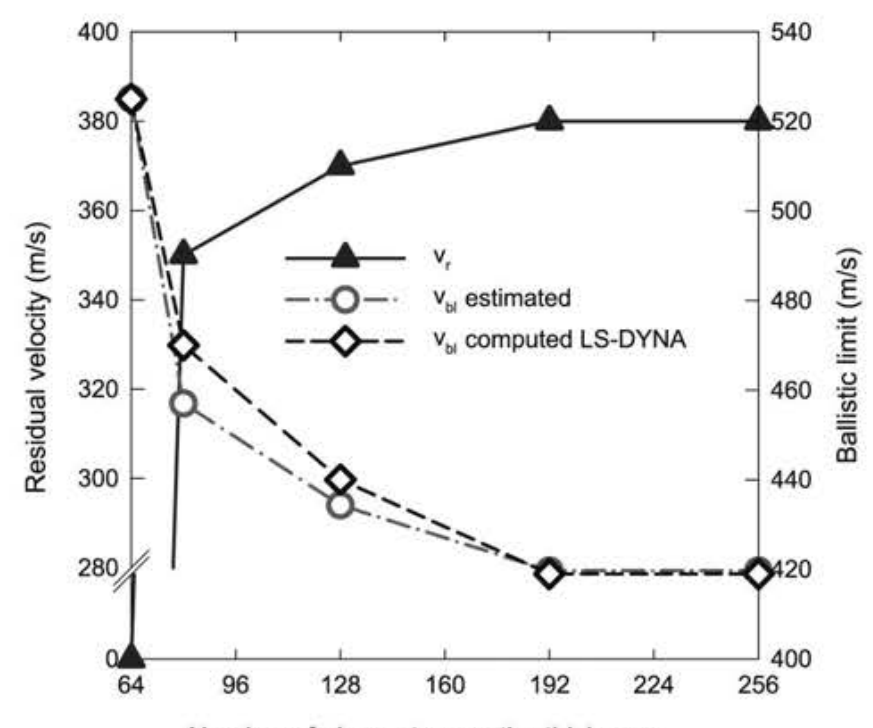

Number of elements over the thickness

Fig. 12. Mesh convergence study performed for the numerical simulations of the ballistic impact tests at room temperature $\left(25^{\circ} \mathrm{C}\right)$. (For interpretation of the references to colour in this figure legend, the reader is referred to the web version of this article.) 


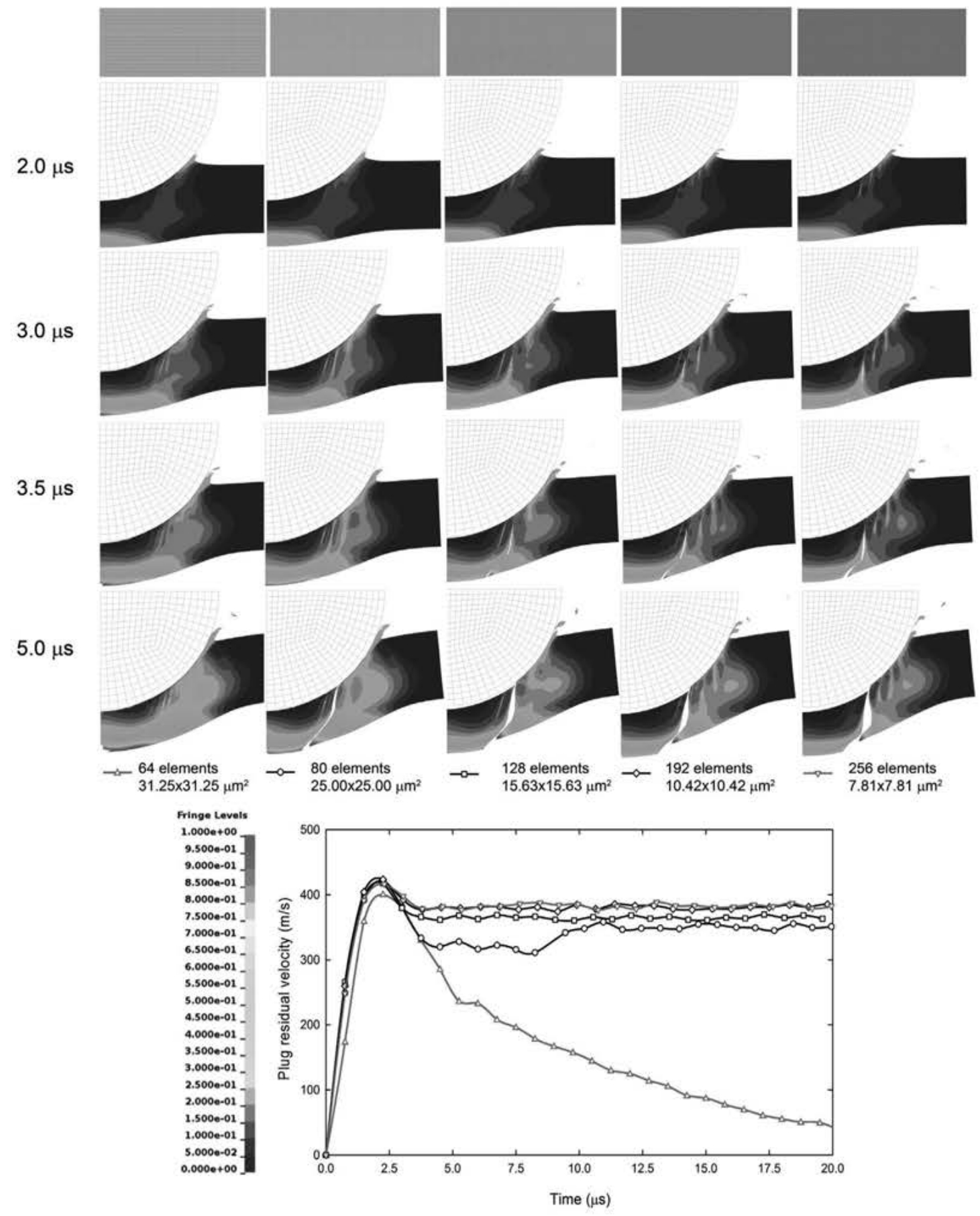

Fig. 13. Effect of the mesh size on shear band prediction. (Up) Damage contours on numerical simulations of the impact test with initial velocity of $525 \mathrm{~m} / \mathrm{s}$. (Bottom) Residual velocity of the plug vs. time for the numerical simulations performed with $64,80,128,192$ and 256 elements across the plate thickness.

Fig. 14. The simulations reproduced accurately the experimental results obtained in the high temperature ballistic tests (see Fig. 15 (b) and (c)). The numerical simulations in the case of room temperature tests were not as good as the previous ones predicting the residual velocities close to the ballistic limit. Nevertheless, the residual velocity prediction slightly above it was found acceptable enough (see Fig. 15(a)).

\section{Conclusions}

A numerical study of ductile failure under quasi-static and impact loadings of precipitation hardened Inconel 718 nickel-base superalloy has been performed. The JCXd elastoplastic-damage coupled constitutive equations with Lode angle dependent failure criterion have been used to model the mechanical behaviour of the superalloy. The material model was implemented in LS-DYNA nonlinear finite element code by means of a user defined material subroutine in fortran programming language. The model constants that were reported in a previous study $[7,26]$ have been employed.

Three series of ballistic impact tests were carried out to validate the proposed JCXd material model under impact loadings. Each one of the series was conducted at a different temperature to check the thermal softening effects in the material. The experiments were carried out at $25^{\circ} \mathrm{C}, 400{ }^{\circ} \mathrm{C}$ and $700{ }^{\circ} \mathrm{C}$. 


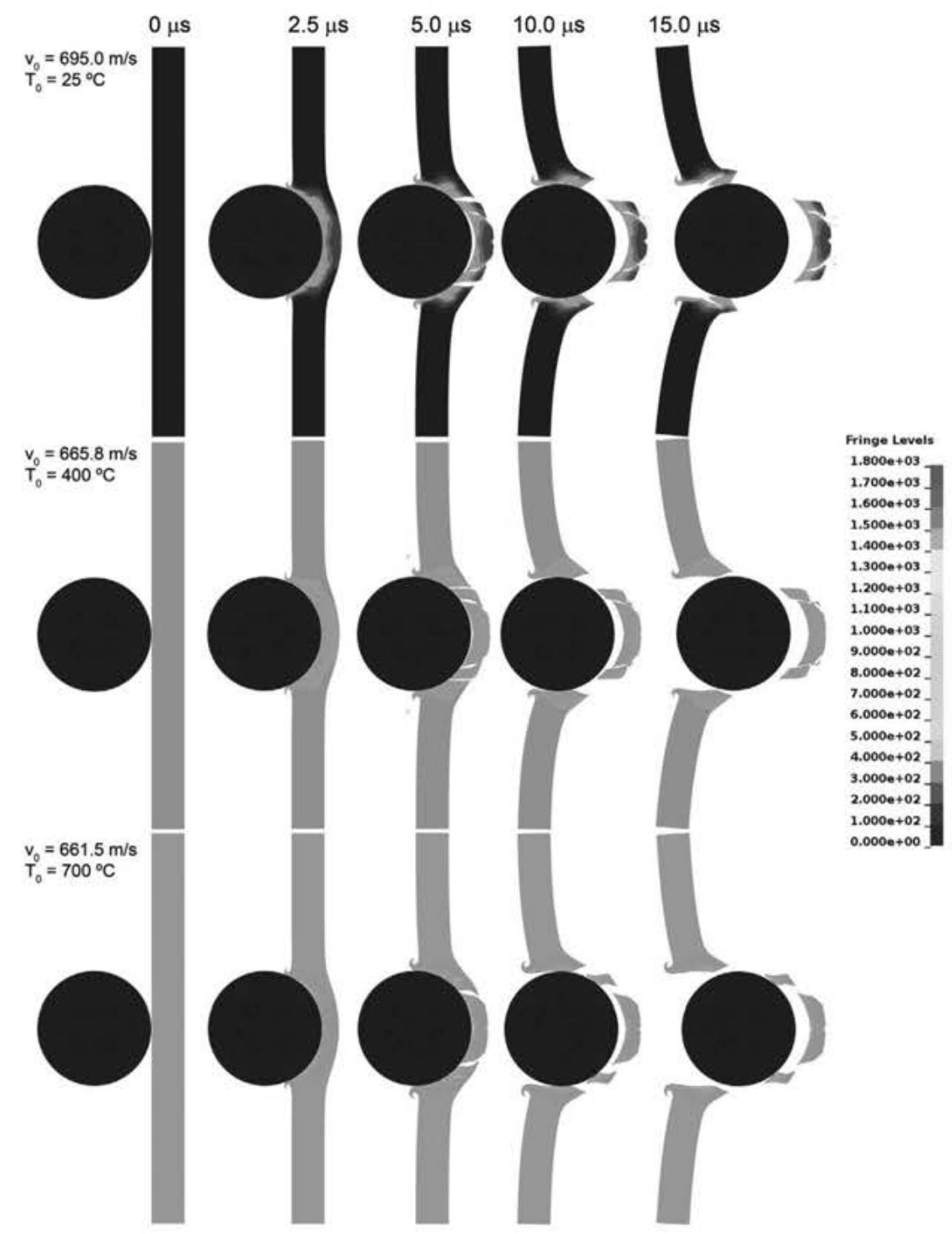

Fig. 14. Temperature contour plots of the numerical simulations of ballistic impact on plates at $25^{\circ} \mathrm{C}, 400{ }^{\circ} \mathrm{C}$ and $700^{\circ} \mathrm{C}$ performed with 192 elements across the plate thickness.

A numerical study on the ability of the JCXd model for fracture pattern prediction under quasi-static loadings was performed. Two reference tensile tests of different specimen geometries were used to carry out such a study: smooth axisymmetric and plane strain specimens. Cup-cone and slanted fracture patterns were expected for the axisymmetric specimen and plane strain specimen respectively. In order to predict them, a very small element size was necessary. The additional parametric study conducted for each one

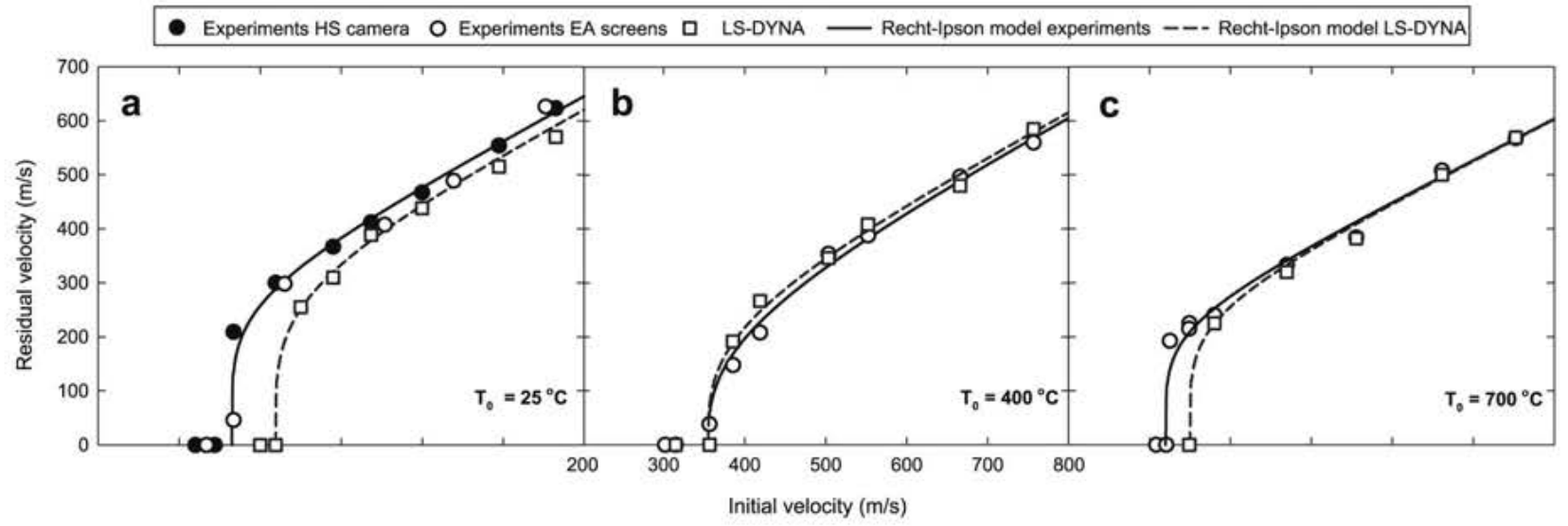

Fig. 15. Numerical and experimental residual vs. initial velocity curves for ballistic impact tests on precipitation hardened Inconel 718 plates performed at (a) $25^{\circ} \mathrm{C}$, (b) $400{ }^{\circ} \mathrm{C}$ and (c) $700{ }^{\circ} \mathrm{C}$. The room temperature tests were measured employing the electrically-activated screens (EA screens) and a high-speed camera (HS camera). 
of the different specimen geometries revealed that the combination of weakened constitutive equations and Lode angle dependent failure criterion was able to predict the fracture patterns, even for such a small element sizes.

Due to the problems that finite element codes have handling extremely deformed elements an additional geometrically-based element erosion criterion was proposed. The criterion was implemented in LS-DYNA and successfully employed for the numerical simulations of plate impacts. The mesh convergence study that has been performed has revealed that the size of it is vital in order to obtain accurate residual velocity predictions. Plugging process in the impacted plates was triggered by the formation of adiabatic shear bands. Therefore, if those bands were not predicted neither was the residual velocity of the plug. The mesh size for which the residual velocity and ballistic limit converged was of the same order that the shear band. The numerical simulations performed with such a discretisation were in good agreement with the experimental data.

Summarising, the mesh size has been found to be a crucial in both quasi-static and impact loading fracture prediction. Further, mesh size should be chosen with care when a rate-dependent material model with thermal softening is used for impact problems.

\section{Acknowledgements}

The financial support that the Secretaría de Estado de Investigación, Desarrollo e Innovación of the Ministerio de Economía y Competitividad has given through the project BIA2011-24445 is greatly acknowledged, as is, the contribution of Industria de Turbopropulsores (ITP)

The authors would like to thank the financial support and contribution to this work from the Structural Impact Laboratory (SIMLab), Centre for Research-based Innovation (CRI) at the Norwegian University of Science and Technology (NTNU). The authors also would like to acknowledge the selfless contribution to this research of Dr. Egil Fagerholt and Professor Tore Børvik.

\section{References}

Bai Y. Wierzbicki T. A new model of plasticity and fracture with pressure and Lode dependence. Int J Plast 2008;24:1071-96.

Gruben G, Hopperstad OS, Børvik T. Evaluation of uncoupled ductile fracture criteria for the dual-phase steel Docol 600DL Int J Mech Sci 2012:62:133-46. Nahshon K, Hutchinson JW. Modification of the gurson model for shear failure. Eur J Mech - A/Solids; 2008:1-17.

Xue L. Constitutive modeling of void shearing effect in ductile fracture of porous materials. Eng Fract Mech 2008:75:3343-66.

Xue L. Wierzbicki T. Numerical simulation of fracture mode transition in ductile plates. Int J Solids Struct; 2009:1423-35.

Bai Y, Wierzbicki T. Application of extended Mohr-Coulomb criterion to ductile fracture. Int J Fract 2010;161:1-20.

Erice B, Gálvez F. A coupled elastoplastic-damage constitutive model with Lode angle dependent failure criterion. Int J Solids Struct 2014;51:93-110.

Xue L. Damage accumulation and fracture initiation in uncracked ductile solids subject to triaxial loading. Int I Solids Struct 2007:44:5163-81.

Johnson GR, Cook WH. Fracture characteristics of three metals subjected to various strains, strain rates, temperatures and pressures. Eng Fract Mech $1985 ; 21: 31-48$.

Johnson GR, Cook WH. A constitutive model and data for metals subjected to large strains, high strain rates and high temperatures. In: 7 th international symposium on ballistics, The Hague; 1983. pp. 541-7.
Livermore Software Technology Corporation (LSTC). LS-DYNA keyword user's manual version 971. Livermore, California: Livermore Software Technology Corporation; 2007. pp. 1-2206.

Xue $\mathrm{L}_{2}$ Wierzbicki T. Ductile fracture initiation and propagation modeling using damage plasticity theory. Eng Fract Mech 2008;75:3276-93.

Xue Z, Pontin MG, Zok FW, Hutchinson JW. Calibration procedures for a computational model of ductile fracture. Eng Fract Mech 2010;77:492-509. Recht RF, Ipson TW. Ballistic perforation dynamics. J Appl Mech 1963:30:38490.

Lambert JP, Jonas GH. Towards standarization in terminal ballistics testing: velocity representation. Aberdeen Proving Ground, Maryland: USA Ballistic Research Laboratory: 1976. pp. 1-51.

DeMange II. Prakash V, Pereira JM. Effects of material microstructure on blunt projectile penetration of a nickel-based super alloy. Int J Impact Eng 2009;36: $1027-43$.

Chocron S, Erice B. Anderson CE. A new plasticity and failure model for ballistic application. Int ] Impact Eng 2011:38:755-64.

Souza EA, Peric D, Owen DRJ. Computational methods for plasticity. theory and aplications. Chichester, West Sussex, United Kingdom: John Wiley \& Sons Ltd; 2008. pp. 1-814.

Belytschko T, Liu WK, Moran B. Nonlinear finite elements for continua and structures. Chichester, England; John Wiley \& Sons, Ltd; 2000. pp. 1-300.

Fagerholt E, Dorum C, Borvik T, Laukli HI, Hopperstad OS. Experimental and numerical investigation of fracture in a cast aluminium alloy. Int J Solids Struct 2010;47:3352-65.

Beese AM, Luo M, Li Y, Bai Y, Wierzbicki T. Partially coupled anisotropic fracture model for aluminum sheets. Eng Fract Mech 2010;77:1128-52. Dunand M. Mohr D. On the predictive capabilities of the shear modified Gurson and the modified Mohr-Coulomb fracture models over a wide range of stress triaxialities and Lode angles. J Mech Phys Solids 2011;59:1374-94. Luo M, Dunand M, Mohr D. Experiments and modeling of anisotropic aluminum extrusions under multi-axial loading - Part II: ductile fracture. Int ] Plast 2012:32-33:36-58.

Luo M, Wierzbicki T. Numerical failure analysis of a stretch-bending test on dual-phase steel sheets using a phenomenological fracture model. Int J Solids Struct 2010:47:3084-102.

Roth CC, Mohr D. Effect of strain rate on ductile fracture initiation in advanced high strength steel sheets: experiments and modeling. Int 」 Plast May 2014:56:19-44.

Erice B. Flow and fracture behaviour of high performance alloys. Madrid, Spain: Universidad Politécnica de Madrid (UPM): 2012. pp. 1-216. http://oa. upm.es/14461/1/Borja_Erice_Echavarri.pdf [Ph.D. thesis].

Besson J. Steglich D. Brocks W. Modeling of crack growth in round bars and plane strain specimens. Int ] Solids Struct 2001:38:8259-84.

LiY. Wierzbicki T. Prediction of plane strain fracture of AHSS sheets with postinitiation softening. Int ] Solids Struct 2010:47:2316-27.

Livermore Software Technology Corporation (LSTC). LS-dyna theory manual. Livermore, California: Livermore Software Technology Corporation, (LSTC) 2006, pp. 1-756.

Dey S, Børvik T, Hopperstad OS, Langseth M. On the influence of fracture criterion in projectile impact of steel plates. Comput Mater Sci 2006;38:17691.

Børvik T, Hopperstad OS, Berstad T, Langseth M. Numerical simulation of plugging failure in ballistic penetration. Int I Solids Struct 2001:38:6241-64. Børvik T, Hopperstad OS, Berstad T, Langseth M. Perforation of $12 \mathrm{~mm}$ thick steel plates by $20 \mathrm{~mm}$ diameter projectiles with flat, hemispherical and conical noses: part II: numerical simulations. Int J Impact Eng 2002;27:37-64. Camacho GT, Ortiz M. Adaptive Lagrangian modelling of ballistic penetration of metallic targets. Comput Methods Appl Mech Eng 1997:142:269-301.

Kane A, Borvik T, Hopperstad OS, Langseth M. Finite element analysis of plugging failure in steel plates struck by blunt projectiles. J Appl Mech-Trans Asme 2009:76.

Kane A, Børvik T, Berstad T, Benallal A, Hopperstad OS. Failure criteria with unilateral conditions for simulation of plate perforation. Eur J Mech $-A / S o l i d s$ 2011:30:468-76.

Dey S, Børvik T, Hopperstad OS, Leinum JR, Langseth $\mathrm{M}$. The effect of target strength on the perforation of steel plates using three different projectile nose shapes. Int J Impact Eng 2004;30:1005-38.

Benallal A, Berstad T, Borvik T. Hopperstad OS. Uniqueness, loss of ellipticity and localization for the time-discretized, rate-dependent boundary value problem with softening. Int ] Numer Methods Eng 2010;84:864-82. 